\title{
Perspecive
}

\section{The Scientific Attitude (The Scientific Temper) in Eastern and Western societies $\$$}

\author{
Arseculeratne SN ${ }^{1 *}$ \\ ${ }^{1}$ Emeritus Professor, Faculty of Medicine, University of Peradeniya \\ $\S$ A lecture given to The Society for the Integration of Science and Human Values, University of Peradeniya
}

\begin{abstract}
The Scientific Attitude, different from the attitude to science, is discussed in relation to Eastern and Western modes of thinking; it is also differentiated from Scientism. The literature from western as well as Indian authors, and the comments of Joseph Needham on China, are included. The topics considered are the history of science, the importance of science, its methodologies, determinants of the growth of modern science, internal and external factors in the growth of science, education in science, documentation of science and technology, and determinants of the modes of thinking about science and its practice: these determinants include religion, tradition, utilitarianism, and administration in science. The major point of contrast between the attitudes of East versus West is argued to be religious versus secular. A relevant bibliography is provided.
\end{abstract}

Key words: Scientific attitude; Scientific temper; Scientism

Copyright: (C) 2014 Arseculeratne SN. This is an open access article distributed under the Creative Commons Attribution License, which permits unrestricted use, distribution, and reproduction in any medium, provided the original work is properly cited.

*Correspondence: chubby@sltnet.lk

Cite this article as: Arseculeratne SN. The Scientific Attitude (The Scientific Temper) in Eastern and Western societies. Anuradhapura Medical Journal 2014;8(1):22-29.

DOI: http://dx.doi.org/10.4038/amj.v8i1.6757 


\section{Introduction}

The Scientific Attitude is a state of mind that enables creative thinking about Nature and natural phenomena, and engaging in valid scientific research on these phenomena; it is not the same as "attitude to science". A discussion of the Scientific Attitude needs to be prefaced by statements on what science is, the steps in the advancement of science that led to Science being now called the greatest intellectual enterprise of Man; also considered are the factors that are inherent in The Scientific Attitude.

\section{What is science?}

Science is, briefly, the systematic exploration of Nature (L. Sciré - to know); the word objective is not added to 'exploration' as it is beset with cultural relativism.

"Science is an activity that seeks to explore the natural world, using well-established, clearly delineated methods". It has to be differentiated from "Scientism"; Scientism, on the other hand, is a speculative world-view about the ultimate reality of the universe, and its meaning" (1).

"It may be that scientism, the idea that scientific truth alone gives understanding of the world, is nothing but a Euro-American disease, and that the great contribution of China may be to cure us by restoring humanistic values based upon all forms of human experience" (2). It is well to bear in mind, what Needham (2) also said: "...what we can rightly object to is the idea that science is the only valid way of apprehending the universe". 'Scientism' may be considered as representing an 'attitudes to science', and an example of Fundamentalism in science.

The following example of Scientism illustrates the problem of some over-enthusiastic practitioners of science who have made a dogmatic religion of science, considering it as the ultimate and only valid view of Nature. They exclude any enterprise however well documented and researched, other than those that fit in with the established paradigms of modern science. I wrote to Richard Dawkins who, despite his well-known book The God Delusion and other books, apparently fell into this category, when he dismissed parapsychology (the Paranormal) and cultural relativism, both of which have been researched for several years and found to have validity, and have been extensively documented (by the present author and others). It was pointed out to him that the attitude of a proper scientist would have been to say "I do not know, let me find out". It is relevant to state that Parapsychology, that was hitherto marginalized by some stubbornly closed-minded practitioners of modern science, was included in the scope of the American Association for the Advancement of Science. It is reassuring that physicist Professor Brian Josephson, Fellow of the Royal Society and Nobel Laureate turned from science to the study of the paranormal and replied, at an interview with BBC as to why he did so, that there was more in that field than conventional science allowed for. Despite the spectacular advances of modern science and its applications, it has sometimes evoked trenchant criticism on reasonable grounds: "He (Theodore Rozak) and the young are against modern science because they feel it has had evil, totalitarian and inhuman social consequences. They are not content to put this down merely to misapplied technology ..." ..."The scientific world-view is thus accused of a cerebral and ego-centric mode of consciousness, completely heartless in its activity" (2). Incidentally, this is the justification for the establishment of this Society for the Integration of Science and Human Values.

A further criticism of science, indeed an example of an attitude towards science, is that it is reductionist, which when parodied led to the comment that "scientists learn more and more about less and less till in the end they know everything about nothing"; I am convinced that a state of proper scientific literacy promoted by a meaningful education will prevent that faulty view.

\section{The importance of Science}

We live in an era of science and science-based technology, expressed succinctly by Jawaharlal Nehru; in paraphrase - I see no way out of our vicious cycle of poverty other than through the means that science has placed at our disposal. In the development of modern India, The Indian Constitution recognized “... the need to promote scientific temper, humanism, the spirit of inquiry and reform, and prescribes it as one of the fundamental duties of its citizens" (3).

\section{Some aspects of the history of Science}

After Alexander's invasion of India in 326 BC, Greek culture influenced Indian culture, in art, literature and astronomy; the Indian scholar Aryabhatta attributed the Zodiac to the Greeks.

Greek civilization is a foundation of western culture. "The Greeks were innovators, inventors. They had a passion for coming to grips with life comprehensively, logically and concretely. Indians were meditative. The Greeks looked outwards, we looked inwards. Withdraw within yourself and meditate, meditate, meditate, that was the Indian panacea for the problems of life. If Aristotle typified Greek civilization, it was Shankara that expressed the quintessence of the Hindu view of life" [4]. "How did this become possible? The reasonable explanation seems to be that the elaboration of the extraordinarily subtle concepts of vedantic idealistic metaphysics led to a tremendous sharpening of the faculty for abstract, 
imaginative thinking of the Brahmins" (4).

Hinduism, in fact, declares that this world is Maya, a delusion and it is the 'other world' that is real"(4). We have to note the excellence of abstract thinking in ancient Indian mathematics. It is noteworthy that not only was ancient technology borrowed by the West from the East but theoretical bases also were transferred (5).

Finally "Scientific advance was made in India precisely by those who rejected all this intuition-mongering masquerading as awe-inspiring occult wisdom (4) .

Despite India's impressive history of metaphysical, religious and philosophical thought, there were the Charvakas (after Charvaka, the leader), the Materialists. Charvaka was an atheist, who sponsored freedom of thought and writing, and 'freedom of conscience' (6). The Charvakas were "secular materialists" (see (7). "The concern of the Charvakas was with natural things and phenomena for their own sake, and explanations for them which, as for the observers in post-Renaissance Europe, were the mainsprings of the development of natural science"(5).

\section{Determinants of the growth of modern science}

There was rudimentary 'science' in the ancient world of India and China, and we now have modern science. Ancient technology including medicine, was essentially empirical. Modern science is a European phenomenon that occurred in the last 400 years, and referred to as The Scientific Revolution. What factors determined the explosive growth of modern science? There are Internalist (Internalism) and Externalist (Externalism) views of the growth of modern science. Internalist aspects include knowledge, motivation, justification, meaning and truth, and in the authors' view, predominantly The Scientific Attitude, imagination and creativity. The critical importance of creativity cannot be over-emphasised [8]. A good example of Internalism was how Auguste Kekule the chemist, solved the core problem organic chemistry, the structure of the molecule of benzene, that has 6 carbon atoms as its basis. He dreamt of a snake biting its own tail and came up with the idea of the ring structure of the molecule of benzene, the back-bone of organic chemistry. Externalist aspects include social aspects, the sociopolitical climate in which scientific thinking is allowed to grow. Porter \& Teich [9] comment: “Joseph Needham's magisterial Science and civilization in China (1954) has aimed to show that, despite her scientific precocity, China failed to pioneer The Scientific Revolution because that empire lacked the socio-political and socio-economic structures and climate of Europe, above all, nascent capitalism".

It can be concluded that (1) for the establishment of a viable national science, both Internalist and Externalist factors are determinants of its growth let alone the survival of science in a country: (2) Modern science is an international enterprise. Roy Porter \& Teich (9) further commented : "No one would dispute that there was a certain internationalism in the pursuit of science in the early modern era... No nation produced the scientific revolution single-handed"; it is for this reason that the terms "Asian" or "Eastern" and "Western science" are not used here. In illustration, some key people, both practitioners and thinkers, in the history of modern science in the West include: Johannes Kepler, Galileo Galilei, Nicolai Copernicus, Francis Bacon, John Stuart Mill, David Hume, John Hobbes, Albert Einstein, T. H. Huxley, Charles Darwin, Robert Boyle, Isaac Newton, Arthur Eddington, Neils Bohr, with Srinivas Ramanujan, P. C. Ray, H. J. Bhabha, H. G. Khorana, S. Chandrasekhar, M. Saha, J. C. Bose, S. N. Bose, C. V. Raman, V. S. Narlikar in India; and analytical commentators like Thomas Kuhn, Karl Popper, A. N. Whitehead, J. D. Bernal amongst others.

The history of modern science indicates that the growth of modern science and The Scientific Revolution occurred in the West, although it had roots in Eastern or Asian civilizations. While there were imports of technological innovations from the East to the West (see (7), it is significant that the East also contributed roots to the theoretical bases of science in the West: de Silva(10) enumerated them as: "...theoretical and philosophical knowledge, algebra, arithmetic, the 'complex phenomenon' of the zero numerical, the decimal system, logic, physics, astrophysics, aspects of biological classification, and ethno-medical systems from South Asia, and especially, from India".

"Modern science was born in Europe, but it's home is the whole world. In the last two centuries there has been a long and confused impact of Western modes upon the civilisation of Asia. The wise men of the East have been puzzling, and are puzzling, as to what may be the regulative secret of life which can be passed from West to East without the wanton destruction of their own inheritance which they so rightly prize. More and more it is becoming evident that what the West can most readily give to the East is its science and its scientific outlook" (11). An Indian author wrote: "It is beyond doubt that some of the major scientific institutions in colonial India were built with participation of scientists who were British or European by birth" (3) .

"But for all that, many leaders of India's intellectual and scientific establishment say, conditions are not such as to encourage or promote the crucial ingredient of science. This is the habit of mind that links curiosity with disciplined, rigorous sustained investigation to expand the limits of knowledge” (12).

\section{The types of science}

The terms Eastern or Western science are not used as science is a universal enterprise; as the title indicates, it is more appropriate to discuss science in the East or science in the West while it is proper to refer to Eastern or Asian 
scientists or western scientists.

Mathematics is considered the queen of the sciences; it underlies quantitation, that is a hall-mark of modern science, certainly in the physical sciences, while it is increasingly being applied in the biological sciences, in medicine, and in psychology as evident in the validation of extra-sensory perception by J. B. Rhine. Parapsychology, the validation of which was contributed to so much by Rhine's work, is now included in the scope of the American Association for the Advancement of Science.

\section{Modes of thinking}

The practice of science is also essentially an intellectual activity. A critical factor that sponsored the growth of modern science was the mode of thinking. The growth of Realism in the West, contrasted with abstract thinking in the East. Paraphrasing Ananda Coomaraswamy, the western mode was to depict Nature as it was and to study it for its own sake, i.e. Naturalism, and not as interpretations of the divine.

Concrete thinking and objectivity rather than subjectivity and value judgements, were dominant; the former characterize the Scientific Attitude. It is however to be noted that the word "objectivity" should be used with caution as it is sometimes qualified by Cultural Relativism. A "balanced skepticism" was prescribed by Carl Sagan in scientific thinking. These are all embodied in the phrase The Scientific Attitude or The Scientific Temper as Jawaharlal Nehru termed it.

Differences in modes of thinking seem to relate to the type of science, for example, abstract thinking that characterized the excellence of Indian mathematical and physical science, though sometimes its natural, especially medical, sciences have shown deficiencies in the modes of thinking related to 'the art of scientific investigation' and the 'logic of scientific inference' as W. I. B. Beveridge and Jennifer Trusted respectively, titled them; these were discussed in the Preface in Arseculeratne \& Atapattu (13). In the latter instances of research, proper planning of experiments, objective analysis of results and some aspects of the philosophy of science, e.g. the idea of Causality, are indispensable .

"Thus, if we assume that the modal locus of Chinese scientists on the abstract/concrete dimension was strongly concrete, we can, I think, account for some features of traditional Chinese science that recur in Needham's descriptions - for instance, the marked disparity between Chinese accomplishments in technology and in theory. An advanced technology presupposes only observation, practical interests, and problem-solving ability; but theory-construction presupposes abstract-bias as well that is, a disposition to direct attention away from concrete reality, with which technology is concerned, and toward ideal models that are not replicated anywhere in nature" (14) . The parallels with Eastern ancient Indian and Sri Lankan technology, for example in the latter's hydraulic achievements, is evident.
"We cannot forejudge what the future developments of the history of science will bring forth, but if India was probably less original than China in the engineering and physico-chemical sciences, Indian culture in all probability excelled in systematic thought about Nature (as for example in the Samkhya atomic theories of kshana, bhutai, paramanu etc.) including also biological speculations" (15). This view emphasizes a characteristic of the pre-modern Indian mode of thought, of having been more concerned with abstract, metaphysical speculation rather than objective experimental investigation. A further feature was the absence of the formulation of hypotheses, and the establishment of the nomothetic bases of even the rudimentary or empirical science at this stage, despite the development of impressive and effective practical applications as in Traditional Medicine (TM); TM contained the roots of advances in later Western medical science, for example, the use of plants, such as Ekaweriya (Sinhala) in India and Sri Lanka, containing reserpine alkaloids in the treatment of hypertension, and the antimalarial quinine in the bark of the Cincona tree in South America, it was left to modern pharmacology to formulate these derivative therapeutic agents. It is to be emphasised that such new developments necessarily availed of parallel advances in allied chemical and biological sciences established in the West.

Modes of thinking, as Hajime Nakamura (16) discussed in his book Ways of thinking of Eastern Peoples. India, China, Tibet, Japan, are a major point of difference between the East and the West; this difference probably underlay the stimulus for the rapid growth of modern science in the West. The consequence was, as Nakamura titled a chapter in his book, the Alienation from the objective natural world, and therefore the absence of the orientation required for the objective study of Nature. On the disparity between Eastern and Western modes of thinking, there appear to be divergent views.

"The rise of Naturalism in the later Middle Ages was the entry into the European mind of the final ingredient necessary for the rise of science. It was the rise of interest in natural objects and in natural occurrences, for their own sakes" (11).

"In his book The meeting of East and West Northrop maintained that a fundamental difference in apprehension of reality divided Asia from Europe. The basis of Eastern culture was said to be intuitive and aesthetic, that of Western culture experimental and scientific while in one place (in) Buddhist Jataka stories and the Russian novel, ( p 64). Wickramasinghe seems to smile upon this opinion, in another (p 129) however, he more thoroughly opposes it, urging that in both East and West there have been materialistic and scientific currents just as there have been religious and idealistic ones...Before I began my own work I had a fairly open mind about this subject, but all that I have since learned seems to contradict the Northrop theory....... " (2).

Arthur Koestler (17), in The Lotus and the Robot) had a similar view: "In the history of the great Asiatic cultures, 
the emphasis lay much more consistently on one side only - on the intuitive, subjective, mystical, logic-rejecting side. This attitude apparently arose out of the equally consistent refusal to recognize the independent reality of the external world. As a result, conceptual thinking could not develop...".

This difference in orientation between Asia and the West expressed itself in drama and art as well.

\section{Drama}

"Let me explain further what I understand by this common concept of drama that seems to exist in Asian civilizations. For one thing, drama, or for that matter, almost any art, has never tried to be naturalistic in the orient. Naturalism in art seems to have had its birth in the West; it appears that naturalism is against the grain of Eastern civilization" [18].

\section{Art}

"The Indian tendency to alienate the objective natural world and to live in the world of meditation also characterizes Indian art. Coomaraswamy says in effect that Indian artists never used models but resorted to imagination in making sculptures ....The very rich and fanciful imagination characteristic of the Indian way of thinking leads them to ignore the common-sense limits of physical possibilities of things in space and time" (16).

\section{Education in science}

Education is the vehicle that conveys and establishes a state of scientific literacy. The matrix of Scientific Literacy has to be understood in the pursuit of a meaningful science education (19). The practice of science in the exploration of Nature results in the discovery of facts, their embodiment in tentative Hypotheses which when further investigated yield Theories. The old view of verification of scientific theories was replaced by Kuhn's more logical view of "falsification" of inadequate theories.

The matrix of Scientific Literacy comprises a knowledge of (1) the history of science, (2) the factual content, (3) the methods used in scientific exploration, (4) the scientific attitude. There is no single "scientific method" (see H. H. Bauer (20), Scientific Literacy and the myth of the Scientific Method); there are several methods for the scientific exploration of Nature.

It can be considered that the sponsorship of originality and creativity (8) in a meaningful education, is a key determinant external factor in the growth or even the survival of science, but which is alarmingly lacking in our education at all levels from primary to tertiary.

A much neglected viewpoint, in both this country and probably in Asia as a whole, is the function(s) of a modern university (as R. B. Hunter titled his essay) which in the Asian world, is based on the British model. These functions include : (a) The establishment (in the sciences) of a scientific culture, (b) transference of the content of science, research, (c) the creation of new knowledge, and (d) the dissemination of science to the public, which is, as Patnaik (3) wrote. "...to make science a cultural force" which "...needs to be perceived as a new value system... in the day-to-day life of the common man".

A feature that underlies nearly all of science education especially at the tertiary level in this country, is the absence of discussions on the philosophy of science, which after all, embodies the intellectual mainsprings of science. It is not inappropriate to recall that I found that none of ten new $\mathrm{PhD}$ holders knew why their degree was termed a "doctorate in philosophy". It is necessary to know that science in the $16^{\text {th }}$ century was called Natural Philosophy. The pitfalls of the ignorance of the philosophy of science in scientific exploration and inference from findings by authors in a prestigious Indian research institution, were illustrated in the Preface to the monograph by the author (13) .

\section{Research and Documentation in science}

Perhaps the most striking difference between societies in the East and the West is in research into natural phenomena and documentation of the findings especially of parapsychological ( $p s i$ ) phenomena. Psi phenomena abound in the East as well as in the West but it was the individual (including famous scientists of the hard sciences) and Societies in the West that pursued scientific investigations; the British Society for Psychical Research was established in the 1830's and the American Society for Psychical Research soon after.

A component that featured in the rapid expansion of scientific thought in the West, was documentation of scientific findings. This has been has already been discussed by the author (5) - "There was yet another factor which nourished the growth of modern science in Europe- the free communication of the results of scientific exploration, within the community of scientists...". In relation to documentation, it also needs to be added that advanced technologies were used in premodern India (steel, cotton, textile weaving --see (21), while hydraulic technology and irrigation were developed in ancient Sri Lanka (that also produced the world's best steel in the $8^{\text {th }}$ century AC (22); yet, Devendra (23) wrote of Sri Lanka: "What is lacking is not scientific knowledge, but treatises written in methods of western people". This was also the case with ancient Sri Lanka's steel technology in the $7^{\text {th }}$ to the $11^{\text {th }}$ centuries: "I did not find any reference to steel making technology in any documentary sources. I was puzzled that there was no reference to what was not only technologically important, but also in my interpretation of the field evidence, economically a very important commodity" (Gillian Juleff 1996, personal communication). Archaeologist Sudharshan Seneviratne (2013, personal communication) agreed that the non-documentation of ancient technology in Sri Lanka is a prevalent view, and explained that architectural lay-outs of monasteries was described in 
manuals (Kashyapa Shilpa), on palm (ola) leaves that were in private collections that were unavailable to the public.

\section{Determinants of modes of thinking}

Some other Externalist factors in the growth or nongrowth of science in Asia, may now be considered.

\section{Religion}

A discussion on the growth of science cannot fail to consider religion as both an Externalist as well as an Internalist factor. "Most of the surviving Indian documents are overwhelmingly religious and ritualistic" (24). The secular nature of the scientific enterprise has been referred to earlier and a dominant question is: "...how did Europe wean itself from religious obscurantism which overwhelmed analytical empiricism, while Asia remained sodden with it....? The divergence of different schools of Asian religion were not substantial, enough, as the reformation in Europe was, to weaken the stranglehold of religious orthodoxy in India" (5). "What was missing in the mediaeval South Asian activity was the '... complete secularization of their discipline (7) " (5). "What were the features of Indian civilization which are claimed to be distinctive? Basically, it is claimed that it gave priority to spiritual aims over material aims"(4). In a nut-shell, the contrast is contained in the phrase, religious versus secular.

\section{Tradition}

"Throughout most of history, in fact, Indian science and culture generally matched and at times exceeded anything anywhere else in the world. But then, conquered by foreigners and immersed in mysticism and worship of the past, India lost its scientific vitality- unfortunately and somewhat ironically, just as the scientific industrial revolution was beginning elsewhere" (12).

"In attempting to explain why scientific research is proceeding so unevenly at the moment, some analysts invoke Hindu India's mystical intellectual cast. They note the Hindu conviction that reality is a never-ending cycle of birth, death and rebirth in which nothing fundamentally new can ever be discovered. This, they say, is contrary to the linear thinking spirit of discovery and the ever-evolving, ever-changing picture of reality that science paints...... But other explanations say that while this may be true, thousand, perhaps millions of Indians have nevertheless shed their mysticism and embraced science. The real difficulties, they say, are more concrete and lie with a variety of structural, institutional, and economic factors" (12) ; these are some Externalist factors.

\section{Caste}

Coomaraswamy in his classic work Medieval Sinhalese Art discusses the influence of caste in Asian technology. Caste is allied to Feudalism. With the heavy underlay of religion in considerations of caste in India, it might be included in the sub-section Religion, above.
Sardesi (4), an Indian author, wrote: "The Brahmanas and Upanishads refer to manual labour with the utmost contempt and bracket the toilers with dogs and swine (e. g. Ch. Upa. 5; 10.8). These very mundane views were developed in and by the Upanishads, intertwined with occultism....Denial of material reality.... considering physical labour as degraded... contempt and hatred for those who worked with their hands,- all the three were inter-connected and went hand in hand with the equation of ultimate reality with pure consciousness, the pure idea, the Atma"; "Enough has been said of the suffocating and fossilising consequences of the caste system. It certainly meant that those who worked by hand had no business to think (to theorise) and those who thought (speculated and theorised) could not touch the spade...Still further impetus to social discontent and to the loosening of the bonds of Upanishadic orthodoxy was given by the indoGreek invasions and the massive tribal immigration of the Shakas and Kushanas who were by no means bound by the hierarchical structure of Chaturvarnya. Taken together, all these factors certainly weakened the grip of brahmanical theories and religion, and of Chaturvarnya as a social system on the masses"... "All religions teach the masses to remain contented with their life on earth as it is, and to look for liberation (salvation) in the world beyond. But no other religion succeeded in developing such a masterly theory for keeping the masses in spiritual and intellectual subjection as Hinduism did through its theory of karma" (4)

The contrast with contemporary China was commented on by Needham (2): "No one who has any acquaintance with Chinese industrial production at the present time, even if only through printed or written accounts, can doubt that a tremendous revolution has taken place in industrial relationships. Artisans, craftsmen, and workers, are encouraged to take initiative, bring forward inventions, tackle jobs cooperatively and manage their own affairs within the framework of a great factory".

The dynamics of a society is thus also a determinant of the growth of science; the differentiation into owners, and capital owners from the vassals, the workers and manual labourers, is considered in Feudalism; "...that is also a vital point, mathematical discoveries and theories do not involve a social conflict between the rulers and the ruled." (4).

\section{Utilitarianism}

Utilitarianism, which is the view of the application of one's endeavour to practical ends and not merely to remain as an abstract, theoretical construct, was also a determinant of scientific activity in the ancient world. "The Chinese had special values related to learning: the most important criterion for learning was its usefulness for humanity (Utilitarianism). This differed strikingly from the ancient Greek, who studied for the sake of knowledge in itself, not necessarily for its direct practical application" (25). 


\section{Administrative obstacles and governance}

As a national enterprise, the establishment of a state of scientific literacy for the practice and application of science, is the onus of governance. Our distinguished diplomat Jayantha Dhanapala was of the documented view that he believed that Institutional Policy was more important than the individual. In a public lecture I refuted him by pointing out that in my experience of science administration in Sri Lanka, it is certainly the administrator who wrecked the programs or on the other hand, contributed to their success. The role of an individual in the development of science at a national level, i.e. the spectacular growth of modern science in India is ultimately attributable to one man, Jawaharlal Nehru, a Natural Science alumnus of Cambridge, who formulated India's National Science Policy statement to the Indian Parliament in 1958, followed by the establishment of the prestigious Indian Institutes of Science.

\section{Conclusions}

A crucial final point on the differentiation between the establishment of the nomothetic bases of the scientific enterprise, expressed in the term scientific literacy, and utilitarianism in their application for technological development, was commented on by Sale (26) : "Even those civilisations (Chinese, Persian, Japanese) that demonstrated a certain proficiency for mechanical inventiveness did not evolve an elaborate abstract system of rationality to go with it - we call it science - and thus did not develop a culture of technology, a self-propelling and self-reinforcing mode of thought that created its own purposefulness and momentum".

All the topics discussed in the sub-sections above indicate that one can speak of a 'sociology of science'; it is axiomatic that the scientific attitude and scientific outlook of a society are the bases of the successful assimilation of science as well as its successful applications. Needham's lecture of 1978 (2) is replete with examples.

\section{Funding}

None

\section{Competing Interests}

None

\section{References}

1. Thomas Burnett. What is Scientism? [Internet]. Washington:American association for the advancement of science.2012.[2014/01/02].Available from: http://www.aaas.org/page/what-scientism. html/

2. Needham J. History and Human Values: A Chinese Perspective for World Science and Technology : Inaugural Martin Wickramasinghe Lecture, 1978; Psychology and Scientific Thought in East and West : a Critical Evaluation of Martin Wickramasinghe's The Buddhist Jataka Sto.Sri Lanka:Martin Wickramasinghe Trust. 1978.

3. Patnaik BK. The Scientific Temper: An empirical essay.New Delhi:Rawat Publications.1992.

4. Sardesi SG.Progress and Conservatism in ancient India. New Delhi:Peoples Publishing House. 1994.

5. Arseculeratne SN. The determinants of the growth of science in pre-modern South Asia. In: Peiris G, de A, Samarasinghe SWR, editors. History and politics. Millennial perspectives. Essays in honour of Kingsley de Silva. Colombo: Law \& Society Trust; 1999.

6. Gandhi Rajiv.Jawaharlal Nehru's Glimpses of World History. New Delhi:Jawaharlal Nehru Memorial Trust.1982.

7. Chattopadhyaya D. Science and society in ancient India. Calcutta:Research India Publications. 1979.

8. Arseculeratne SN. The Problem of Creativity. Presidential address, Section A. Sri Lanka Association for the Advancement of Science 1978.29-38.

9. Porter R,Teich M.The Scientific Revolution inNational Context.Cambridge:Cambridge University Press. 1992.

10. De Silva MAT.Evolution of technical innovations in ancient Sri Lanka. Colombo:Centre for Endogenous Research and Development.2011.

11. Whitehead AN. Science and the modern world. London:Free Association Books. 1985.

12. Anon.Cultures, Knowledge's and Developments, a historical perspective. In: Ancient roots, New shoots: endogenous development in practice. Haverkort B, Van't Hooft K,Hiemstra W(Eds). London:Zed Books. 2003.( quoted in The Island 16 Jan. 1983. India tries to regain scientific creativity).

13. Arseculeratne SN, Atapattu DN. Rhinosporidiosis in Humans and Animals \& Rhinosporidium seeberi. 2011: 328-32. 
14. Jones WT. World Views and Asian Medical Systems. In: Leslie C, editors. Asian medical Systems. A comparative study. Reprint. California: University of California Press. 1976.

15. Needham J. Psychology and scientific thought in East and West. Colombo.Sri Lanka: Martin Wickramasinghe Trust. 1978.

16. Nakamura H. Ways of thinking of Eastern Peoples. India, China, Tibet, Japan.revised edition. London: Routledge .1997.

17. Koestler A.The Act of Creation. $1^{\text {st }}$ edition. London: Four Square Books.1964.

18. Fernando Ml. in the Ediriweera Sarachchandra Memorial Lecture II. Colombo.2000. (quoting ER Sarachchandra in his lecture, 1957 Tokyo)

19. Arseculeratne SN.Scientific Literacy: Its meaning and significance. Keynote address, $8^{\text {th }}$ Asian symposium, International Council of Associations for Science Education, and in Scientific World 1993:384; 1 - 6.

20. Bauer HH. Scientific literacy and the myth of the Scientific Method. Chicag: University of Illinois Press. 1992.

21. Alvares CA. Decolonizing history: technology and culture in India, China and the West 1492 to the present day. $3^{\text {rd }}$ edition. New York: The Apex Press;1991.

22. Gill J. An ancient wind-powered smelting technology in Sri Lanka. Nature 1996; 379: 60-63.

23. Devendra DT.Tanks and Rice. Colombo: MD Gunasena \& Co.1965.

24. Kosambi DD. The culture and civilization of ancient India inhistorical outline. New Delhi: Vikas.1986.

25. Selin H. Encyclopaedia of the history of Science,technology and medicine in non-western cultures. Vol 1. Boston: Kluwe Academic. 1997.

26. Sale K. The Conquest of Paradise:ChristopherColumbus and the Columbian legacy. London:Papermac.1991.

\section{Submit your next Manuscript to Anuradhapura Medical Journal}

Submit your manuscript at

www.sljol.info/index.php/AMJ/ 